\title{
Tension Points in Real Social Science: A Response
}

Bent Flyvbjerg, Todd Landman, and Sanford Schram

Full reference: Flyvbjerg, Bent, Todd Landman, and Sanford Schram, 2013, "Tension Points in Real Social Science: A Response," British Journal of Sociology, vol. 64, No. 4, December, pp. 758-762, DOI: 10.1111/1468-4446.12047_4.

URL: http://onlinelibrary.wiley.com/doi/10.1111/1468-4446.12047_4/abstract

Social science today often contents itself with trying to explain particular events in terms of general models without understanding those events as experienced by the people being studied and without providing findings that might help people address the problems they are experiencing. It can be argued that the recent development of social science has focused too much on its own 'evidence-inference methodological core' and has lost sight of what is being studied, who is being studied, and how the results of research can challenge popular understanding, misconceptions, and power relations. At the most basic level, our edited volume Real Social Science: Applied Phronesis (Cambridge, 2012) is designed to provide examples of research that is situated in real communities, grows out of the concerns of people in those communities and is conducted in ways that can help those people address those concerns. These examples demonstrate that what we are calling "phronetic social science" (as originally coined by Bent Flyvbjerg) offers a meaningful approach for making social science useful and relevant to real people experiencing real problems. Phronetic social science calls for social scientists foregoing the attempt to build generic models of social behavior and instead situate their work in ongoing political struggles as they occur in specific contexts.

The three short essays in this symposium on issues raised by our collection are most welcomed not just for their generous compliments but also for their thoughtful criticisms that help move the debate about our work further. The key issue is what to make of the idea of phronetic social science now that it is associated with a growing number of research projects across the social sciences. In our volume, we suggest that the case studies provided by our colleagues highlight how phronetic social science is not just context-specific and designed to be relevant to addressing issues people are confronting, but that it is research that is sensitive to power relations and the tension points that those power relations create. Focusing on tension points, we suggest, is key to making phronetic social science useful. These tension points highlight how power relations are standing in the way of addressing the particular problems being studied. The same can be said for this response. We focus on selected tension points our commentators have provided in the name of helping to make progress on moving phronetic social science forward. (Our commentators have given us much to consider but space limitations prevent us from considering all.)

Our first tension point comes from Brian Caterino's ideas of 'mutual understanding' and 'collaboration' between researchers and actors. He appears to be arguing that phronetic social science must have these features, but we disagree. Phronetic researchers may decide such mutual understanding will form part 
of their research, but phronetic research itself can be done (and indeed already exists) that is without such mutual understanding. For us, the notion of mutual understanding in phronesis is the understanding among the reference group to which the researchers consider themselves to belong, i.e., the group that shares the same concerns as the researchers; and this group may or may not include actors. The same argument applies to collaboration. Phronetic social science may engage in collaboration but it does not have to in order for it to be phronetic. Beyond this major tension point with Caterino, we object to the ideas that a phronetic researcher must be a 'superior individual' and 'stand above' the moral commitments of participants. In both cases, we do not see the phronetic researcher as superior or above that which he or she studies, rather he or she may remain 'outside' the moral commitments of participants; a position that is in our view more consistent with Foucault.

The second major tension point comes from John Gunnell's thoughtful essay questioning our understanding of the relationship of theory to practice (and by extension, research to social action). Gunnell shares with us a concern about reification, or how much of social science modeling ends up studying reified models of its subject matter without giving due appreciation that these are at best heuristic devices and not the thing in itself. Gunnell's mention in this regard of Max Weber's concerns about Economics as a discipline is entirely consistent with our understanding of how social science is best when it puts reified models aside and situates its investigations in specific contexts as experienced by the people being studied. Part of our reasoning is that the subject matter of the social sciences is how people on the ground are experiencing social relations, and this is not reducible to abstract, universal causal models. Gunnell's complaint with our version of what he calls this "interpretive" approach is that it draws on an outdated and repudiated model that distinguishes the natural sciences from the social sciences. For Gunnell, both the natural sciences and the social sciences are interpretive in that they provide interpretations of the subject matter being studied. The difference for Gunnell is that while the natural sciences "present" an interpretation of their subject matter, the social sciences "represent" interpretations of the interpretations the people being studied. We agree on this distinction between the natural and social sciences and also agree that social science needs to be sensitive to the problems of reification. If we take this tension point seriously, it can move phronetic social science forward by making the clash of interpretations (within a political community or social setting, but also between researchers and the people being studied) a key focus for getting at what impedes action to address a problem.

A third major tension point comes when Gunnell worries aloud that phronetic social science is at risk of repeating the failures of the past in trying to make social science matter. For Gunnell, social science best gives up the hope of being political, taking sides, trying to be relevant, etc. Instead, it is best when it sticks simply to trying to offer a clear understanding of what is being studied. Theory is theory and practice is practice. Here the tension point is inflected. We disagree in that social science as an interpretive enterprise cannot but be involved in the offering of interpretations that people are using to make sense of their experiencing. Social science is in this sense relevant whether it wants to be or not. The question is whether it will perform its relevance effectively. Clarifying what counts as a good interpretation is itself taking sides, engaging in advocacy and proposing solutions. Michel Foucault popularized the term "discursive practices" to highlight how theory was imbricated in practice and vise 
versa. The theory/practice divide is as Gunnell suggests a non-issue but not necessarily in the ways that he states. To theorize, to engage in research, to interpret social action is ineliminably a form of that social action and when done in ways that are directly connected to specific social struggles it becomes part of that struggle. Phronetic social science grows out of a specific context of social struggle so as to further attempt to resolve those conflicts, and to do so by focusing on interpretive tension points in particular. Phronetic social science operates as a more systematic, reflexive, even meditative moment within social struggle, not something apart from it. The very idea of a discursive practice suggests that this is how it should be (making phronetic social science not an unnatural violation of the theory/practice divide).

Despite our agreement with much of what Gunnell writes there are remaining areas of difference that we would like to address. First, he argues that the necessary institutional transformation for making social science matter is likely to come from the top, but history shows us that there are countless examples of real institutional transformations that have been sustained precisely because they have come from below (e.g. the struggle for citizenship rights, improved labour conditions, women's rights, gay rights among many others). There is a real opportunity for contributing effectively to similar transformations from the kinds of social science we have assembled in this volume. Second, Gunnell argues that we advocate for a social science that has the capacity, ability and opportunity to intervene in social practices akin to the ways in which natural scientists seek to control nature. In fact, our position is exactly the opposite. Third, he makes a rather ethnocentric argument that somehow the phronetic approach would only really work in contexts with which we are intimately familiar (i.e. Aalborg, Denmark), while we have shown throughout the chapters in Real Social Science and in particular in our discussion of tension points that the phronetic approach must always be adapted and modified to fit particular contexts, such as the work that Flyvbjerg has done in Africa and Landman in China, mentioned in the book. Finally, we contest the comparison of our enthusiasm for the phronetic approach to Mormon missionaries and Jehovah Witnesses, as both these communities are based on faith, and the one obvious demonstration in our volume is the real empirical difference the phronetic approach has made to the research process and research results detailed in the case studies.

The final major tension we wish to highlight here comes from Ed Soja whose essay focuses penetratingly on the importance of spatiality for phronetic social science. Soja appropriately notes the Ranu Basu contribution to our volume entitled "Spatial Phronesis." Yet, he is concerned that we did not integrate her focus on spatiality into our overall explanation of phronetic social science, leaving us vulnerable of being accused of re-inscribing the longstanding social science prejudice against space in preference of privileging time. In this regard, we are happy to stand corrected and thus need to highlight more the importance of how space is constructed in social science research, while at the same time recognizing the variation in how space is used across different country contexts. We can think more about how to theorize context so that specialization can be accounted for. Yet, as with much of the phronetic approach, we resist modeling. We do not want to specify a model of how to do phronetic research for that would undercut the idea that it should be something that varies with the context, otherwise it would not be context sensitive. That said, context specific research needs to be sensitive to the role of 
how space is being constructed and how the people being studied understand social relations spatially. We thus agree that space deserves its place in phronetic research.

As we write for this symposium, the US Senate has passed an amendment to the Continuing Appropriations Act of 2013, which if sustained will limit National Science Funding to political science only to those projects that are focused on national security and the economic interests of the United States. The conscious abolition of funding to such fundamental topics of political research, such as voting, elections and democracy (among many others such as the use of the filibuster) shows that there is now an even greater need to take on board a political science (and a social science more generally) that engages with its subject matter and challenges entrenched interests in the ways that we believe the essays in Real Social Science do. The further demonstration of the value of the phronetic approach found in this new volume shows how, why and under what conditions social science research can matter, while our hope is that the bottom-up institutional transformation made possible through phronetic social science continues to be embraced by an increasingly larger number of individual social scientists. 